\title{
High-pressure biotechnology in medicine and pharmaceutical science
}

\author{
Patrick Masson, ${ }^{{ }^{\star}}$ Carole Tonello, ${ }^{2}$ and Claude Balny ${ }^{3}$ \\ ${ }^{1}$ Centre de Recherches du Service de Santé des Armées, Département de Toxicologie, \\ Unité d'Enzymologie, BP 87, 38702 La Tronche cédex, France \\ ${ }^{2}$ Hautes Pressions Technologies, Chemin des Romains, 55000 Bar le Duc, France \\ ${ }^{3}$ INSERM U128, IFR24, CNRS, 1919, route de Mende 34293 Montpellier Cédex 5, France
}

\begin{abstract}
High-pressure (HP) biotechnology is an emerging technique initially applied for food processing and more recently in pharmaceutical and medical sciences. Pressure can stabilize enzymes and modulate both their activity and specificity. HP engineering of proteins may be used for enzyme-catalyzed synthesis of fine chemicals, pharmaceuticals, and production of modified proteins of medical or pharmaceutical interest. HP inactivation of biological agents is expected to be applicable to sterilization of fragile biopharmaceuticals, or medical compounds. The enhanced immunogenicity of some pressure-killed bacteria and viruses could be applied for making new vaccines. Finally, storage at subzero temperatures without freezing is another potential application of HP for cells, animal tissues, blood cells, organs for transplant, and so forth.
\end{abstract}

\section{INTRODUCTION}

Pressure is an important environmental parameter. More than $70 \%$ of the Earth's surface is covered by oceans (average hydrostatic pressure: $0.4 \mathrm{kbar}$ (The official pressure unit (SI) is Pascal $(\mathrm{Pa}): 1$ bar $=10^{5} \mathrm{~Pa}$ ), where abyssal organisms are adapted to pressure and low temperatures $\left(1^{\circ} \mathrm{C}-3^{\circ} \mathrm{C}\right)$. Those living close to hydrothermal vents, where the temperature can be higher than $100^{\circ} \mathrm{C}$, are hyperthermophiles adapted to high pressure. Enzymes of these organisms, called extremozymes, have potential biotechnological applications. Lessons from natural extremozymes should help to design stable mutants of mesophilic enzymes capable of working with enhanced catalytic efficiency under extreme conditions of pressure and temperature. The observation that pressure can inactivate barosensitive microorganisms, and the dramatic effects of pressure on macromolecular systems are at the origin of highpressure biotechnology born in Japan the early 90s where it has been first applied to food preservation and processing [1-3]. Now this emerging technology has reached maturity, and its sphere of application is growing up. The purpose of this review is to stress potential pharmaceutical and medical applications of high-pressure biotechnology.

\section{EFFECTS OF PRESSURE ON CONSTITUENTS OF LIVING MATTER}

These effects have been extensively reviewed in recent years [1-5]. The behavior of biosystems under high hydrostatic pressure is governed by Le Chateliers' principle, which predicts that pressure favors processes accompanied by negative volume changes, and conversely, inhibits processes accompanied by positive volume changes.
In the pressure range of biotechnological interest, pressure has, in general, no effect on covalent bonds. Therefore, natural compounds such as flavors, aromas, dyes, and pharmacologically active molecules are not destroyed by highpressure treatment at room temperature. Several provitamins and vitamins ( $\beta$-carotene, thiamin, riboflavin, folic acid, ascorbate, retinol, tocopherol) have been found to resist to pressures as high as $6-8 \mathrm{kbar}$. Cycloadditions such as DielsAlder reactions, accompanied by large volume contractions, are accelerated by pressure. It was shown that these reactions could promote the destruction of vitamins $\mathrm{K}$ and coenzyme $\mathrm{Q}$ at elevated pressure $(6.5 \mathrm{kbar})$ and temperature $\left(70^{\circ} \mathrm{C}\right)$.

Pressure acts also on the structure of membranes, biopolymers, and multimacromolecular assemblies because of actions on noncovalent bonds. Hydrophobic interactions, the most important weak bonds involved in the stability of proteins, micelles, and lipids are differentially altered by pressure. Formation of hydrogen bonds is associated with small volume contractions and reinforced under pressure. Ionic bonds are disrupted by pressure. Ionization of acids, bases, salts, and self-ionization of water is increased under pressure. Nucleic acids and polysaccharides are pressure-resistant because their secondary structure is mainly stabilized by $\mathrm{H}$-bonds that are almost pressure insensitive. Proteins are the most pressure sensitive biomolecules $[5,6]$, as it will be shown in the following sections.

\section{PRESSURE DENATURATION}

Like heating, pressure can denature proteins. Pressure denaturation is a complex multistep process, depending on the pressure range, the rate of compression and the exposure 
time to pressure. Studies of protein temperature-pressure dependence showed elliptic phase diagrams [5]. Pressures lower than $3 \mathrm{kbar}$ inactivate enzymes but do not cause extensive conformational changes in protein structures. Moreover, in some cases, there is evidence that moderate pressures induce conformational transitions toward compact partially unfolded states called "molten globules" (MG) [7].

The formation of homogeneous protein gels, polysaccharide gels, and protein-polysaccharide mixed gels under pressure is of great interest in cosmetology and pharmaceutical applications. Pressure gels and flocculated emulsions of proteins can be used for their particular rheological properties or as carriers for the slow-release of trapped active compounds. Study of the effects of pressure on thermoresponsive synthetic polymers should help to master the controlled assay times. Finally, application of pressures around $2 \mathrm{kbar}$ has been used for reversing aggregation of misfolded proteins and inclusion bodies, and increasing proper refolding. This has been successfully applied to recombinant proteins of pharmaceutical interest.

\section{CHEMICAL MODIFICATIONS OF PROTEINS AND OTHER MACROMOLECULES}

Proteins can be chemically modified under pressure to link aromatic groups. This leads to easily emulsifiable proteins. Interestingly, the formation of brownish melanoidines is pressure-inhibited. The Diels-Alder addition reaction can be used for the chemical modification of proteins or for selective bioimmobilization of proteins and biologically active molecules. Such adducts could be used as drug delivery systems or as biological components in biosensors.

Enzyme modification of proteins and polysaccharides can be achieved under pressure. In particular, pressure can modulate enzyme activity such as the specificity of proteases. The partial proteolysis of milk proteins has been applied to increase their digestibility [1].

\section{ENZYME-CATALYZED CHEMICAL REACTIONS}

Enzyme reactions under high pressure or in supercritical $\mathrm{CO}_{2}$ are a new and promising aspect of enzyme engineering $[8,9]$. The enzyme-catalyzed synthesis of pharmaceuticals under mild conditions has proved to be possible. In particular, the enantioselective synthesis of esters such as ibuprofen esterification by lipases, pharmacological peptides by thermolysin [10], polyols, and sweeteners seems to be interesting. These reactions are performed in bioreactors at pressures, in general, lower than $2 \mathrm{kbar}$, i.e., pressures that do not alter the stability and functionality of enzymes. By operating in the presence of stabilizing cosolvents or in organic media, it can be possible to increase the thermobarostability of industrial enzymes [11].

Pressure can be turned to account to promote reactions catalyzed by naturally occurring enzymes in plant cells. For instance, pressure was found to favor the hydrolysis of glucosynolates of cruciferous plants. This leads to bioactive isothiocynates. Glucoraphanin from broccoli juice can be converted to sulforaphane, which displays antitumor activity and nematocidal properties [12]. Such reactions can be used for food functionalization and for producing "nutraceuticals" to be used in complementary therapy.

The high-pressure processing could be used for the stabilization of heat labile neutraceuticals in natural products, e.g., vitamins. Moreover, the antimutagenic potencies of vegetable juices, presumably due to peroxidase activities, are only partly reduced by pressures from 6 to $8 \mathrm{kbar}$, for carrots, cauliflower, kohlrabi, leek, spinach, beet, and tomatoes. The anticarcinogenic activities of these vegetable juices are more or less heat sensitive but they are resistant to a pressure of $4 \mathrm{kbar}$ at room temperature, a pressure industrially used for stabilization of low acid products.

Pressure processing was found to be efficient to reduce the allergenic activity of food. One of the three known allergenic structures of celery root is destroyed at $6 \mathrm{kbar}$ and $20^{\circ} \mathrm{C}$. The Echigo-Seika company has been marketing for several years a hypoallergenic precooked rice. This patented process applicable to rice could also be used for wheat and barley processing [13].

\section{PRESSURE-ASSISTED FREEZING AND THAWING AND STORAGE AT SUBZERO TEMPERATURE WITHOUT FREEZING}

The solid-liquid phase diagram of water shown that water remains liquid down to $-20^{\circ} \mathrm{C}$ under a pressure of $2 \mathrm{kbar}$ [4]. Several applications of the effect of high pressure on the phase transitions of water are currently under development in food technology and more recently for possible applications for the preservation of biopharmaceuticals, blood derivatives, cells, and organs for transplant. A 1960 study showed that pressureassisted thawing could improve the survival rate of slowly frozen human conjunctiva and chick skin cells [14].

The freezing induction of a product cooled at temperature from $-10^{\circ} \mathrm{C}$ to $-20^{\circ} \mathrm{C}$ under a pressure of $1 \mathrm{kbar}$ to $4 \mathrm{kbar}$ is quite instantaneous when pressure is release. Less structural damages are noticed for products frozen with the help of pressure than with $-30^{\circ} \mathrm{C}$ air or with liquid nitrogen at atmospheric pressure. This technique has been used for cryofixation of samples for electron microscopy. It could probably allow fragile biopharmaceutical products to be frozen without damage.

The properties of water under pressure allow also bioproducts to be stored at subzero temperature without freezing. The process (an increase of pressure up to 1-2 kbar, followed by a cooling and a reheating before depressurization) has less dramatic effects than freezing and thawing processes. The contaminating microorganisms and spoiling enzymes are reduced during this subzero temperature nonfrozen storage.

\section{INACTIVATION OF BIOLOGICAL AGENTS}

High pressure causes inactivation of vegetative microorganisms through membrane modifications, inactivation of 
key enzymes, and inhibition of protein biosynthesis [15]. Although some bacterial strains are known to resist at pressures higher than $8 \mathrm{kbar}$ [16], the combined action of pressure and moderate heat could be used for sterilizationpascalization-of heat sensitive products, liposomes, cosmetic products, and even small surgical or endoscopic tools. Bacterial spores are very resistant to pressure. However, their inactivation can be achieved by associating heat and/or chemical treatment with pressurization [3].

Viruses are very sensitive to moderate pressures between 1 and $3 \mathrm{kbar}$ [17]. Inactivation of numerous viruses such as herpes viruses and immunodificiency viruses [18] by pressure has been successful. Combining pressure, low temperature, and urea can facilitate the disassembly of viruses. Among possible applications are inactivation of viruses in biological compounds, sterilization of biological materials, blood, and tools. The use of high pressures in decreasing the virus concentration in blood of patients suffering severe virus infections such as AIDS by ex vivo pressure treatment of blood has also been proposed.

Nonconventional agents, i.e., misfolded isoforms (scrapie, $\mathrm{PrPsc}$ ) of cellular prion proteins ( $\mathrm{PrPc}$ ), are very stable. They can resist treatment at $160^{\circ} \mathrm{C}$ for up to 24 hours. However, preliminary results showed that the prion protein responsible for the Syrian hamster spongiform encephalopathy can be inactivated by pressures higher than $5 \mathrm{kbar}$ (Cléry, Masson, Dormont, unpublished data, 2000). However, complete and safe inactivation of prion proteins would probably need application of pressures higher than $10 \mathrm{kbar}$, which preclude practical use with commercially available equipments.

\section{DEVELOPMENT OF VACCINES}

Pressure-induced unfolding of proteins unmasks antigenic sites and may increase immunogenic properties of pressure treated proteins, killed viruses and microorganisms. Basset and colleagues at the Paris Institute Pasteur carried out first researches on the use of pressure to make vaccinal proteins. In mid-fifties, a vaccine against polyomyelitis was almost ready [19]. For economic reasons, these works ended quickly, after the Sabin vaccine was launched on the market. In the past few years, pressure has regained interest in the development of vaccines against viruses and malignant cells. In particular, inactivation of Rift valley fever virus (RVFV) at $2.75 \mathrm{kbar} / 25^{\circ} \mathrm{C}$ in $30 \mathrm{~min}$ showed that the immunogenetic capability of pressure-inactivated viral particles is higher than that of formaldehyde-treated virus; mice which were vaccinated with pressure-treated virus were protected against infection by wild-type RVFV [20].

\section{CONCLUSION}

High-pressure bioscience is now a field that is growing up. In addition to the increasing number of basic publications and international conferences, very active international HP networks are building up. This is stimulating because the development of the HP biotechnology requires knowledge in many scientific and technological fields, from physics to medicine through biology, chemistry, and material sciences. In a very near future, it can be expected that a better understanding of the pressure effects on biomolecules and living cells will permit progress and development of the HP technology in medicine and pharmacy.

\section{ACKNOWLEDGEMENTS}

This paper was written within the framework of the European COST action D10.

\section{REFERENCES}

[1] Balny C, Hayashi R, Heremans K, Masson P, eds. High Pressure and Biotechnology. London \& Paris: John Libbey Eurotex; 1992.

[2] Hayashi R, Balny C, eds. High Pressure Bioscience and Biotechnology. Amsterdam: Elsevier; 1996.

[3] Ludwig H, ed. Advances in High Pressure Bioscience and Biotechnology. Berlin: Springer-Verlag; 1999.

[4] Mozhaev VV, Heremans K, Frank J, Masson P, Balny C. Exploiting the effects of high hydrostatic pressure in biotechnological applications. Trends Biotechnol. 1994;12:493-501.

[5] Mozhaev VV, Heremans K, Frank J, Masson P, Balny C. High pressure effects on protein structure and function. Proteins Struct Func Gene. 1996;24:81-91.

[6] Gross M, Jaenicke R. Proteins under pressure: the influence of high hydrostatic pressure on structure, function and assembly of proteins and proteins complexes. Eur J Biochem. 1994;221:617-630.

[7] Masson P, Cléry C. Pressure-induced molten globule states of proteins. In: Hayashi R, Balny C, eds. High Pressure Bioscience and Biotechnology. Amsterdam: Elsevier; 1996:117-126.

[8] Kunugi S. Enzyme reactions under high pressure and their applications. Annu NY Acad Sci. 1992;672:293304.

[9] Kamat SV, Beckman EJ, Russell AJ. Enzyme activity in supercritical fluids. Crit Rev Biotechnol. 1995;15:41-71.

[10] Kunugi S, Kitayaki M, Yanagi Y, Tanaka N, Lange R, Balny C. The effect of high pressure on thermolysin. Eur J Biochem. 1997;248:567-574.

[11] Rariy RV, Bec N, Klyachko N, Levashov AV, Balny C. Thermobarostability of $\alpha$-chemotrypsin in reversed micelles of Aerosol OT in octane solvated by water-glycerol mixtures. Biotechnol Bioengn. 1998;57:552-556.

[12] Butz P, Tauscher B. Recent studies on pressure-induced chemical changes in food constituents. High Pessure Res. 2000;19:11-18.

[13] Inoue T, Kato Y. Jpn Patent no H6-7777; Internat. Patent no WO92/11772. 1990.

[14] Taylor AC. The physical state transition in the freezing of living cells. Ann NY Acad Sci. 1960;85:595-609.

[15] Abe F, Kato C, Horikoshi K. Pressure-regulated metabolism in microorganisms. Trends Microbiol. 1999;7:447-453. 
[16] Garcia-Graells C, Hauben KJA, Michiels CW. Highpressure inactivation and sublethal injury of pressureresistant Escherichia coli mutants in fruit juices. Appl Environ Microb. 1998;64:1566-1568.

[17] Silva JL, Foguel D, Da Poian AT, Prevelige PE. The use of hydrostatic pressure as a tool to study viruses and other macromolecular assemblages. Current Opin Struct Biol. 1996;6:166-175.

[18] Jurkiewicz E, Villas-Boas M, Silva JL, Weber G, Hunsmann G, Clegg RM. inactivation of simian immunodeficiency virus by hydrostatic pressure. Proc Natl Acad Sci USA. 1995;92:6935-6937.

[19] Basset J, Lépine P, Chaumont L. Effet des hautes pressions sue le virus de la poliomyélite (source Lansing). Ann Inst Pasteur. 1956;90:575-596.
[20] Perche PY, Cléry C, Bouloy M, Burkhart MF, Masson P, Michel P. Study of inactivation and immunogenicity of Rift valley fever virus type 13 clone treated by high hydrostatic pressure. Am J Trop Med Hyg. 1997;57(3S):256-257.

* Corresponding author. E-mail: pymasson@compuserve.com Fax: +33 4 76636963; Tel: +33476636959 

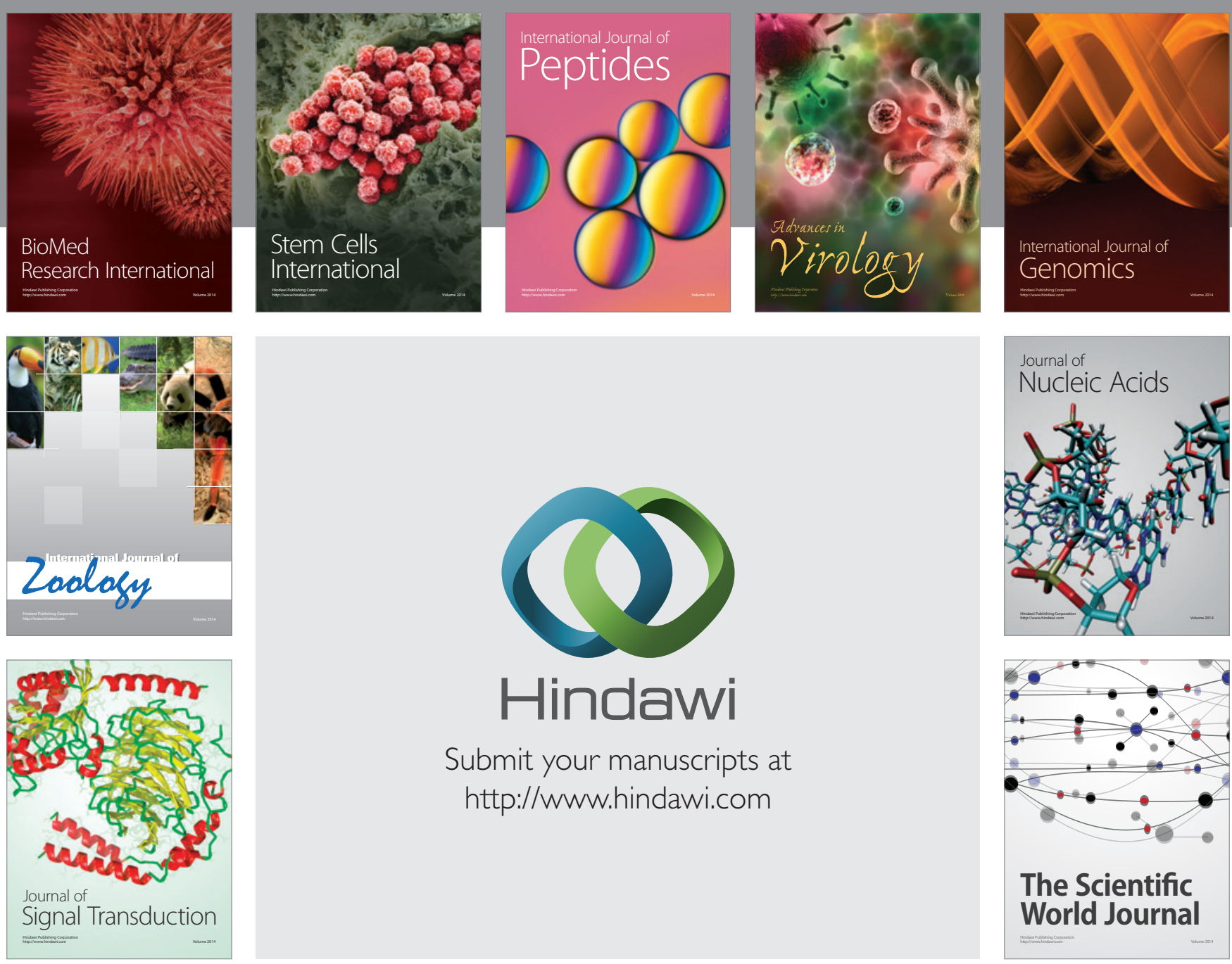

Submit your manuscripts at

http://www.hindawi.com
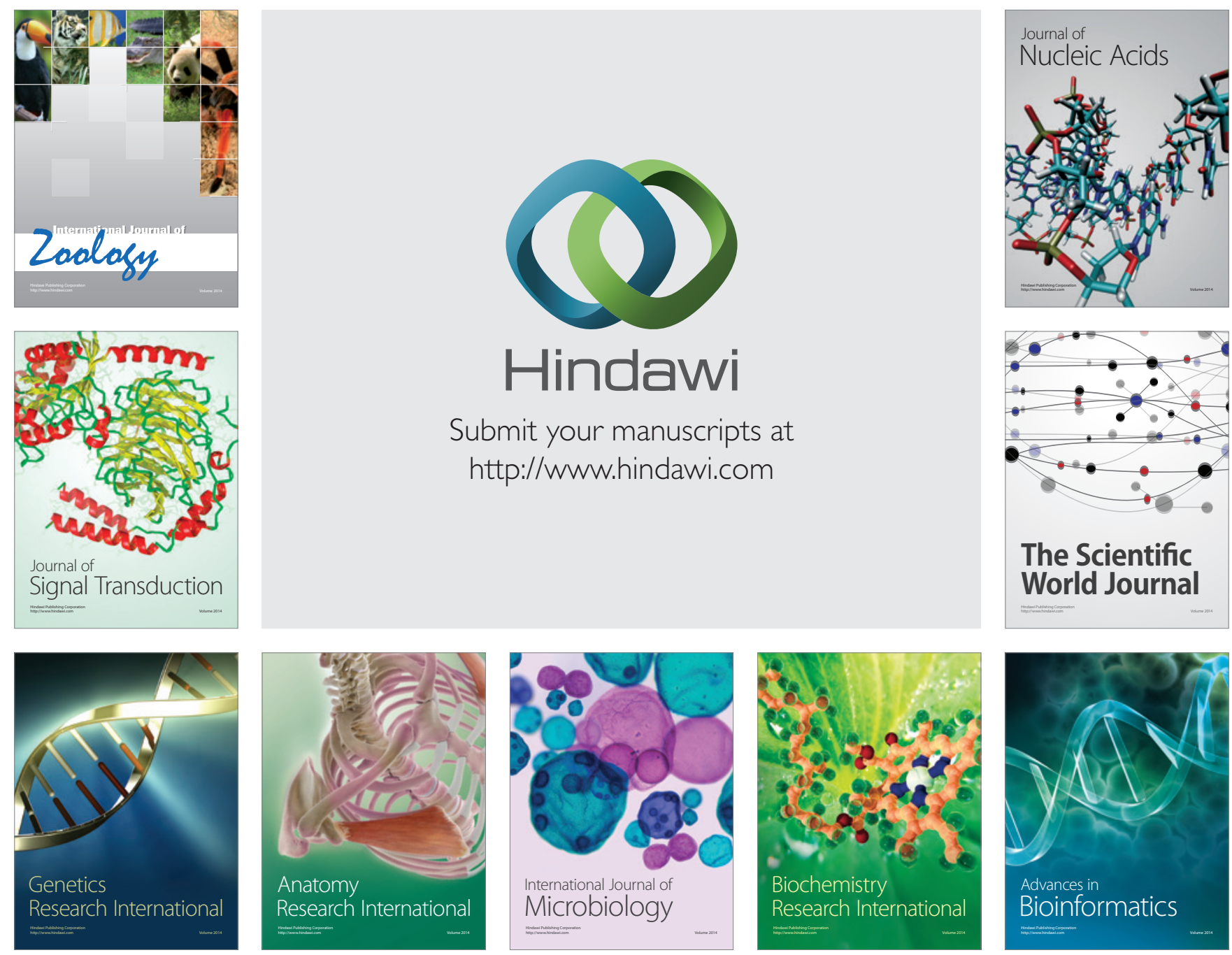

The Scientific World Journal
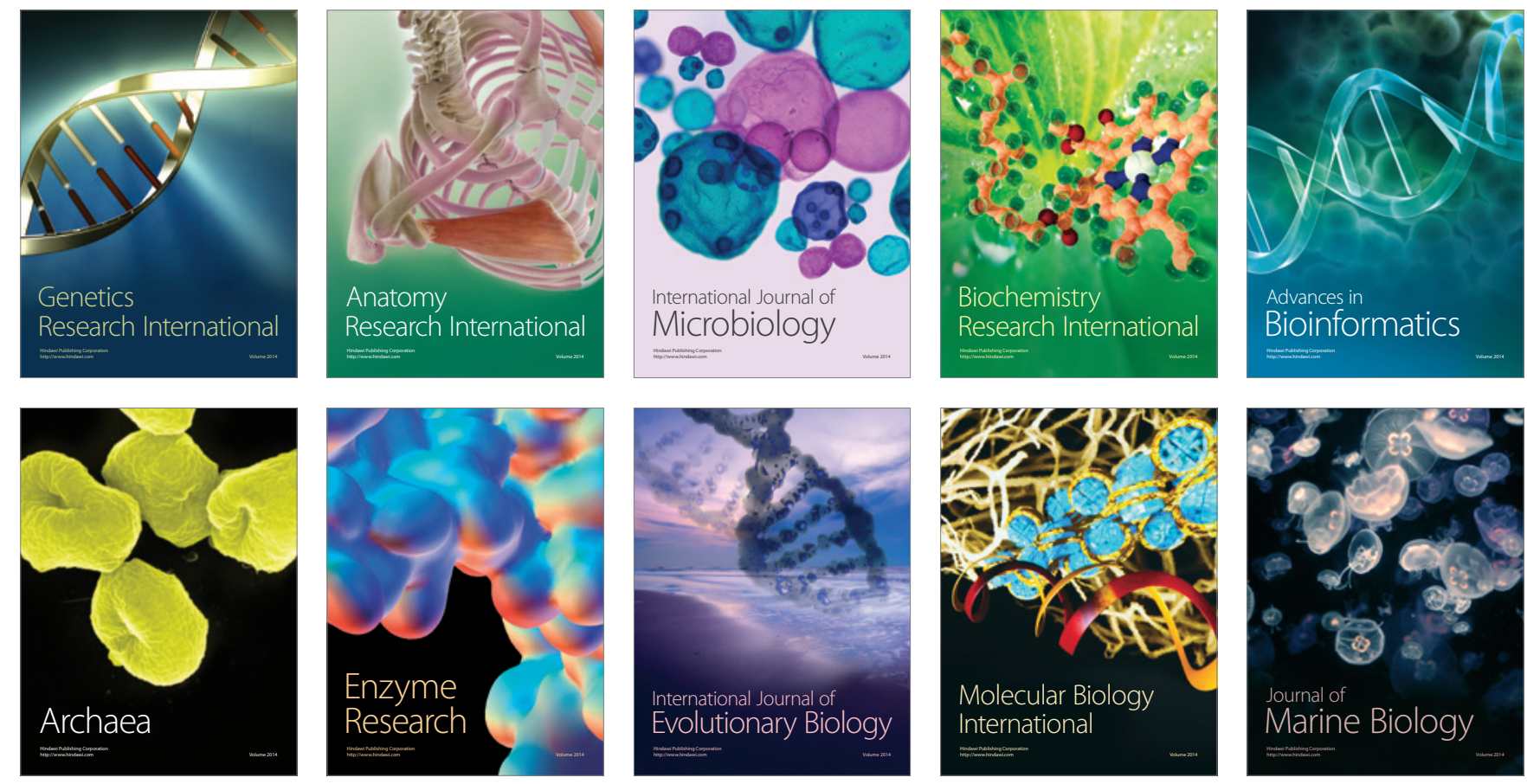